\section{form $A \times A D E$ ENISS}

Vol I4, No 2 (202I) https://doi.org/10.7577/formakademisk.4200

Priska Falin

Doctoral candidate

Aalto University

priska.falin@aalto.fi

Nur Horsanali

Master of Arts

Independent Designer nur.horsanali@gmail.com

Flemming Tvede Hansen

Associate Professor (PhD)

The Royal Danish Academy

fth@kadk.dk

Maarit Mäkelä

Associate Professor (DA)

Aalto University

maarit.makela@aalto.fi

\title{
Practitioners' Experience in Clay 3D Printing
}

\section{Metaphorical viewing for gaining embodied understanding}

\begin{abstract} potentials fall naturally into place.

Keywords:

Practice, Experience, Clay 3D printing, Embodied understanding, Metaphor
\end{abstract}

In the context of artistic research, making has been traditionally understood as a process between the maker and the material. However, the digitalization that influences all practices brings us new kinds of making processes in which the 'digital tools' have a profound impact on the practitioner's experience also in the context of art, craft and design. This study explores the maker's experience from a practiceled approach to understanding the subjective experience with clay 3D printing. To open up the 3D printing process with clay using our embodied understanding, the full process is viewed metaphorically - borrowing from music. The preliminary findings show that metaphorical viewing and the use of a score enables a successful review of the nature of computer-based practices in a way that all aspects and 


\section{INTRODUCTION}

In the context of artistic research, experiential knowledge or knowing has been researched from the perspective of professional practitioners (Mäkelä, 2007; Nimkulrat, 2009; Niedderer, 2007). There has been an attempt to open the tacit aspects of knowing gained during and through the acts of making. Also, the goal has been to explicate the nature of human understanding, which has a strong foundation in being in the world, pointing in the direction of embodied cognition (Groth, 2017).

In these discussions, the making process has been understood, for example, as a dialogue (Mäkelä, 2016) or negotiation (Aktaş \& Mäkelä, 2019) between the maker and the material. The connection between the practitioner and the material has been discussed widely using different notions in the current discussions, where the material is seen as a co-designer (Aktaş, 2018). The current articulation proposes that there is an agency in the non-human world (Malafouris, 2008), giving credit to others - such as materials - in the context of making. All these theoretical framings on making use examples that originate from close or direct contact with materials. In addition, the examples are usually based on the artist-researcher's own practice and have the nature of artistic or craft practices that connect with material world either directly or through the use of tools that are often understood as extensions of the hand (Pallasmaa, 2009; Maravita \& Iriki, 2004). Nevertheless, these theoretical discussions on making in artistic research tend to bypass the element of technology when concentrating on the close connection with materials within practices. In contemporary practices with digital tools, the focus is heavily on the software/hardware, even more than materials. This difference in the experience of making calls for a closer examination of the character that digital tools impose on creative practices.

In this paper, the use of different software and hardware is examined as an elemental part of the creative practice. This has shown how the use of digital tools changes the experience of the maker in a profound way. It is relevant to understand the importance of the embodied nature of knowing and close connections to materials as a tool for discussing embodied understanding (Johnson, 2015). This engagement in material processes is central when reflecting on traditional practices (Falin, 2014). In this research, the maker's experience is reflected against the current theorization of making. The practice that this paper explores is reflected upon from the artistic research point of view with the aim of understanding the different nature that digital tools have. The background for understanding the nature of making stems from what are frequently termed 'traditional practices', where the maker and the material have close connections. In this paper, the term 'contemporary practice' refers to making based on digital tools such as computer software, a 3D printer or a laser cutter.

This paper uses a practice-led approach to understanding the maker's experience in clay 3D printing. The experiences of clay 3D printing are reflected on with the use of metaphors borrowing from the field of music. As Yamamoto et al. states: "People usually experience music a part of their everyday life in different forms: listening to music, playing music or composing music" (Yamamoto, Y., Uchiyama, H., \& Kakehi, Y., 2011). In this paper, we use the idea of the making of music metaphorically to consider clay 3D printing. The paper also introduces the concept of score, also borrowing from music, to visualize the act of making of clay 3D printing. The gathering of information for this new understanding of clay 3D printing was carried out by two makers: a ceramic artist (Author 1 ) and a designer (Author 2). Author 1 was concentrating on the practitioner's experiences in clay 3D printing and Author 2 contributed by creatively exploring the process through improvisation. In this paper, they share and develop their findings.

The leading question throughout the paper is: how does metaphorical viewing help to engage with an unfamiliar process? The assumption is that using our existing embodied understanding, which is already embedded in conceptual metaphors, helps to create an idea of the unknown in the way that reveals possibilities concerning how to engage with it. In the paper Tying Knots: Creating Metaphors for Interpersonal Relationships (2019), therapist and educator Knut Omholt creates a language for understanding relationships through the practice of knot making. In his paper, Omholt suggests that "one can strengthen one's abstract thinking by engaging bodily with concrete phenomena" (ibid., 2019, p.4). Cognitive linguist and philosopher George Lakoff and philosopher Mark Johnson (1999) talk about the conceptual metaphor and say that it "allows the use of physical logic or grasping to reason about 
understanding" (p.45). This paper continues the discussion on how to harness our embodied knowledge through the use of metaphors.

\section{DIGITAL TOOLS}

Faced with new digital tools there has been a fear of losing practical knowledge when the 'making' changes. In this context, Malcolm McCullough, author of the book Abstracting Craft: The Practiced Digital Hand (1998), argues for the importance of the knowledge behind the act of making, the practitioner's knowledge and how it has value also in making with new digital tools. Designer Katie Bunnell $(2004, p .1)$ points out that in a post-modern society there is importance in the authenticity that products following craft-based methodology embodies.

Digitalization is growing rapidly and all that can be digitized probably will be in the near future (Fors, 2010). Currently, practitioners who have been focusing on merely 'material hands-on working', are facing this digitalization and questioning how to deal with it: whether to embrace it or refuse to work with it. The 'machine', as a notion, often has negative implications for craft-rooted makers, stemming from the industrial change in human history where "weavers, bakers, and steel-workers have all embraced tools that eventually turned against them" (Sennett, 2008, p.81). Thus, when considering the new technologies, it is apt to ask how they will change the traditional ways of making. However, being a new tool for the practitioner, the clay 3D printer contains the potential for change in the practice (Sennett, 2008, p.210). This change itself can be a motivator for practitioners to challenge themselves and explore new tools. Understanding the change can provide valid knowledge when entering the postdigital era, meaning that the digital is already intertwined with the physical world (Dufva, 2018).

Digital tools are increasingly used in creative practices and in the studio context. From this perspective, the experience of the maker and engagement when making has value concerning how the technology will be adapted and accepted as a part of the practices. Digitalization brings many new tools for the maker, which changes the traditional close connection to materials and appears to increase the distance between the maker and the material (Hansen \& Falin, 2016, p.117). Still, the full potential of the technique and the material usage that the technique enables is little explored by designers and artists, and only some research is focused on the studio context when it comes to making with, for instance, 3D printers (Hansen \& Tamke, 2019; Klein, 2008).

Nevertheless, McCullough (1998) argues that craft and work with digital tools has a lot in common concerning hand and brain activities. In addition, making with digital tools has been framed as digital crafting. The discussions often focus on what kind of understanding is needed from the perspective of materials (Thomsen et al, 2012, p.11), for example, and how the techniques and digital tools can be explored creatively (Hansen \& Tamke, 2019). Understanding the experience of the making process itself has value for adapting and engaging with contemporary practices.

This paper recognizes the differences that making with digital tools has compared to traditional practices and suggests that the hesitation displayed towards contemporary practices has its origins in a lack of understanding of making as a process. Without any experience in clay 3D printing, for example, this elusive process of actual making is hard to imagine and reflect on. In his doctoral dissertation, Visual Artist and Art Educator Tomi Dufva (2018) examines creative coding using art educational methods. Dufva recognizes a similar difficulty in grasping the digital surroundings (Dufva, 2018, p.7). Dufva \& Dufva write in their paper Grasping the future of the digital society (2019) that an embodied understanding of the digitalisation is needed in order to be more empowered in the society that is permitted by the digital technology (p.25).

\section{THE EXPERIENCE OF A PRACTITIONER}

For an artist working with ceramics, the roots of learning and understanding the material and its processes are heavily intertwined with hands-on making. Looking into the experience of making and the aesthetic qualities in the context of making is also primarily connected to the close connection with materials (Falin, 2014). When discussing the experience of a maker, the focus tends to move towards 
the aspect of enjoyment. The enjoyment in making is often connected to the making processes and how the maker experiences them (Hansen \& Falin, 2016, p.116). The enjoyment of hands-on making is understandable when considering such issues as the tactile feel of materials and how the maker connects with the making processes on an intrinsic level (Falin, 2014). The consequence is that there is something in the material or the processes of making that comes naturally for the practitioner. Such enjoyment when employing contemporary practices with their close connection to technology rather than materials is not evident for the practitioner. The difference that the practitioner experiences between working with traditional and digital tools also stems from the fact that the tool is profoundly different (Figure 1). The difference compared to traditional tools is that the digital tool is programmed (Rushkoff, 2010). There are different sets of skills needed in contemporary practices. In clay 3D printing, the full score (as later defined, see Figure 7), the whole act of making is combining the new skills with the traditional ones as a practice that also informs the programming.

When thinking of a digital tool, there is an expectation that the tool will perform without any errors. This line of thinking comes from the industrial way of manufacturing and in that context, it is natural to be able to rely on the processes of production. In creative practices, however, mistakes and other problems are very common with digital tools. There can be mistakes in the original digital file, or the printer might have problems with its mechanics or programming or simply there may be unexpected failures in the network.

In this paper, the theoretical frame for understanding the maker's experience is drawn from the concept of aesthetic experience (Dewey, 2005). Through the thinking that "the aesthetic experience can reach the consciousness in a revealing manner", the maker's experience is examined (Falin \& Falin, 2014). Herein, the aesthetic experience covers both traditional and contemporary practices. The similarity lies in the organic act of expression where the maker brings all her prior experiences and understanding with her to the making along with emotions such as passion and qualities such as sensitivity and aesthetic perception (Dewey, 2005, p.51). The differences come through when thinking of the enjoyment, use of skills and the material environment (including digital material); this changes the dynamics of the felt experience.

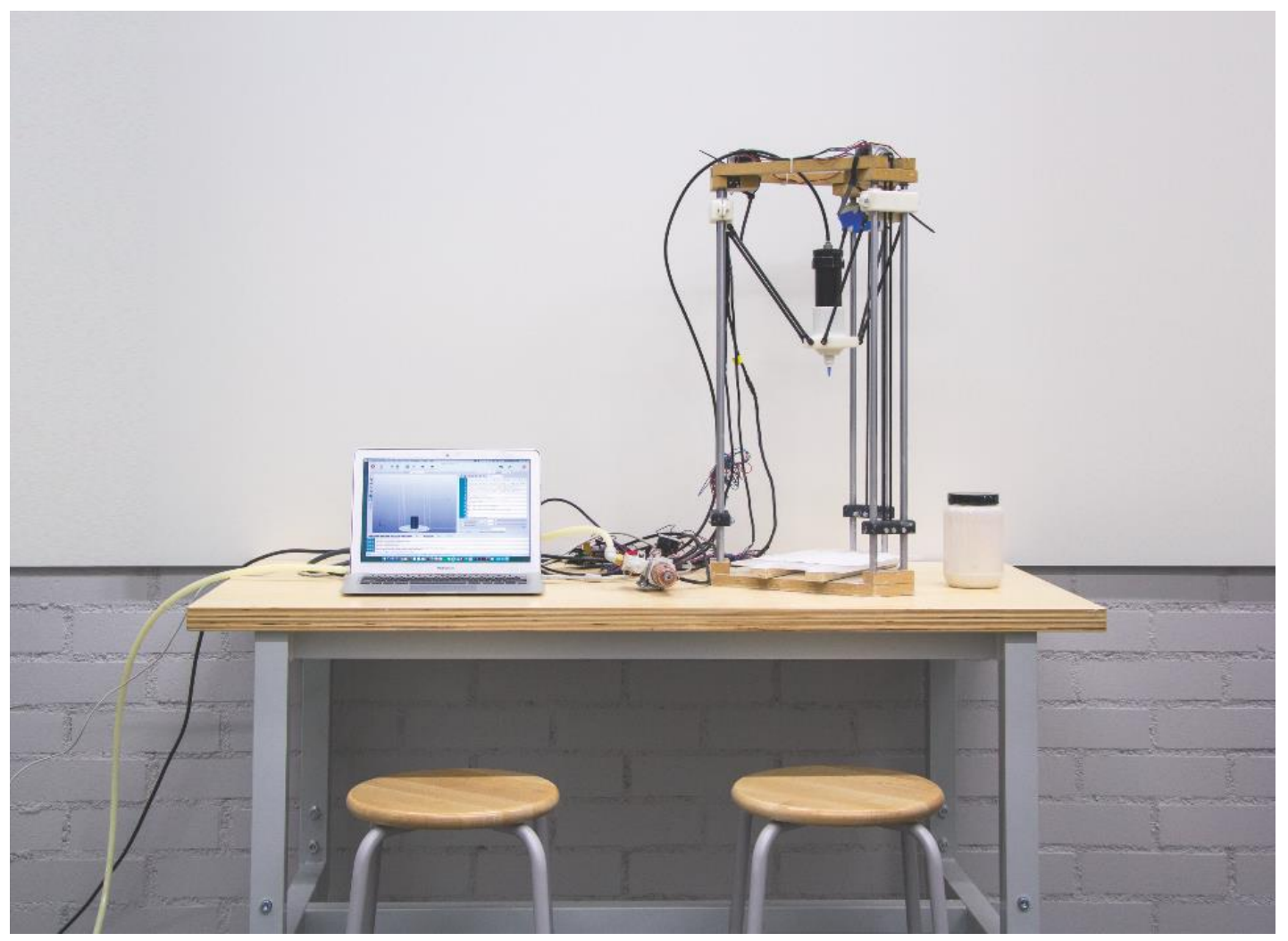

FIGURE 1. Digital tools: Printing set-up at the university workshop. Photo: Nur Horsanali, 2019. 
Through traditional making, for example when starting to mould clay with one's hands, the making can be an open-ended process, where the direct connection to material is an elemental part. In this kind of making, the embodied knowledge of the practitioner plays an important role. In comparison, when creating the digital file, the digital environment is not bound by physicality. It offers another kind of freedom for the practitioner.

Social Anthropologist Tim Ingold conceives of making as a practice of weaving (2010). He refers to the concept as the textility of making, whereby the maker intervenes in the flows and force-fields of material and binds her own previous experiences and lifeworld with the material flows, resulting in the textility of making and by doing so arrives at the outcome of the making (Ingold, 2010, p.92). This corresponds very well to aesthetic experience. When reading about the act of making described by Ingold, it is extremely close to human beings in the sense that physicality and the material world are very present in his examples, such as the splitting of timber (Ingold, 2010, p.92). The theorization of the making itself is rooted in what and how humans naturally do and make. The material flows are also rooted in this point of view regarding what is natural for us to perceive as flows and material properties.

Entering the space of digital materiality is a profoundly different experience compared to haptic and sensual interaction with the material world. Therefore, the possibilities, thinking, actions, aesthetics and embodied relatedness are all different in nature. In the following, the paper focuses on clay 3D printing as an example of contemporary practices.

\section{THE 3D PRINTING PROCESS}

3D printing is a process that transforms the digital file into clay or other solid materials. The printer reads the information that is fed into it and interprets it as movements and material additions. There is a large field of different kinds of techniques in 3D printing, but the closer focus that this paper has is on the technique that is a layer printing technique based on coiling. The "form" that is fed into the machine as digits, is coiled up layer by layer (Figure 2).

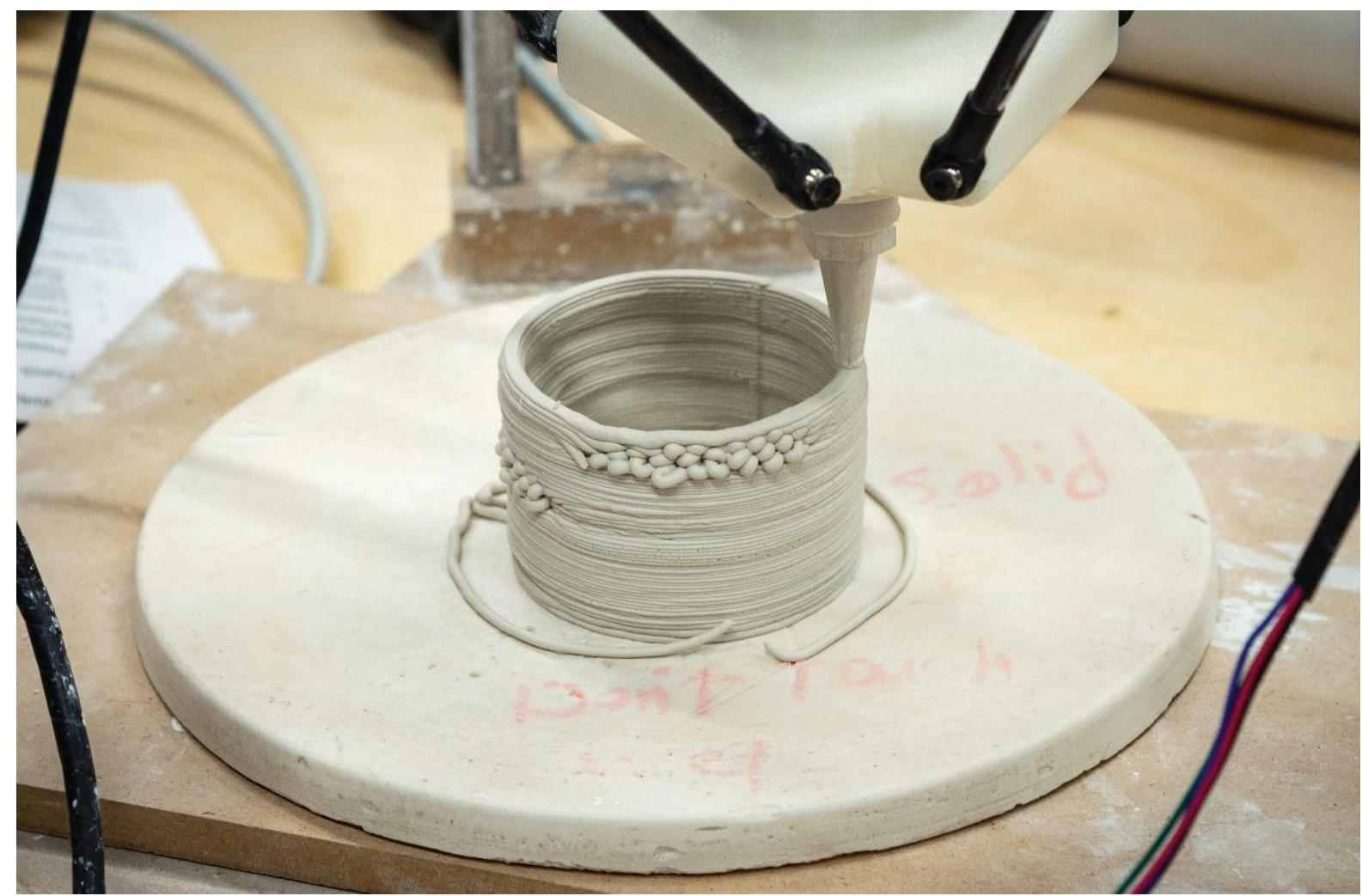

FIGURE 2: The process of clay 3D printing. Photo: Minerva Juolahti, 2019. 
The printing process begins on the computer with the form being created using 3D CAD software, such as Rhinoceros. After this, a G-code needs to be generated which is a common open-source programming language that communicates information to the digital tool on how the 3D form will be constructed. In order to generate a G-code, it is common to use slicer software. There are also plug-ins available that can aid in generating the g-code directly from the modelling environment without the use of a slicer (see more Gürsoy, 2018, p.25). After the generated G-code is transmitted to the printer, the form starts to build up, layer by layer. As Verbruggen (2014) puts it, 3D printing is a technology that can bridge the "digital, screen-based world with the physical, material world" (p.174). In one example, Hansen (2013) created a voice reactive application for generating a g-code with pre-designed parameters.

Unlike the usual 3D printing process in plastic, 3D printing in clay is usually a constant transition between hands-on and digital experiences of making. Before starting printing, the clay "needs to be meticulously prepared and loaded inside large syringes", and during the printing, "material flow needs to be guarded and adjusted" (Verbruggen, 2014, p.176). After printing, the process continues as with traditional ceramics practice: finishing the surface, bisque firing, glazing and high firing. This 'postprocessing' with printed clay objects, also opens up the possibility of continuing working with the object, for example reshaping it (Gürsoy, 2018, pp. 22 and 27).

For the purpose of this paper, authors 1 and 2 have used their experiences from a practice-led approach to clay $3 \mathrm{D}$ printing. The printer used was a self-built delta printer constructed according to the instructions of the ceramic artist Jonathan Keep. The experience, process and results of this printer are distinct from the commercial printers due to its DIY (do-it-yourself) nature and partly makeshift elements. Additionally, this printer requires the continuous control of air pressure by hand, which can connect the maker to the tool better, having a hands-on experience in making, and it can create a mechanism for improvising (Horsanali, 2019).

\section{METAPHORICAL VIEWING OF THE PROCESS}

According to Bjerstedt (2014), "art forms, or artists, tend to mirror themselves in each other in order to understand themselves better" (p.28). In this paper, we use (the making of) music metaphorically in order to gain an embodied understanding of the full process of clay 3D printing. For visualizing the process of clay 3D printing, we borrow the concept of a 'score' from the field of music for our own field. In music, the term 'score' refers to the written notation of a musical work. A score can be for a single or many different parts or instruments. For the purposes of this paper, a full score is of interest.

A full, or orchestral, score shows all the parts of a large work, with each part on separate staves in vertical alignment ..., and is for the use of the conductor. (The notation for each performer, called a part, contains only the line or lines he or she is to perform.) Thus, the conductor can see at a glance what each performer should be playing and what the ensemble sound should be. Usually, the score consists of musical notations in which each instrumental or vocal parts are in vertical alignment. (Encyclopædia Britannica, 2017)

In this paper, the maker can be thought of as the conductor of the 3D printing process. Figure 3 shows the full score for an orchestra where the composition is written for different parts that perform together (Damibaru, 1850). 


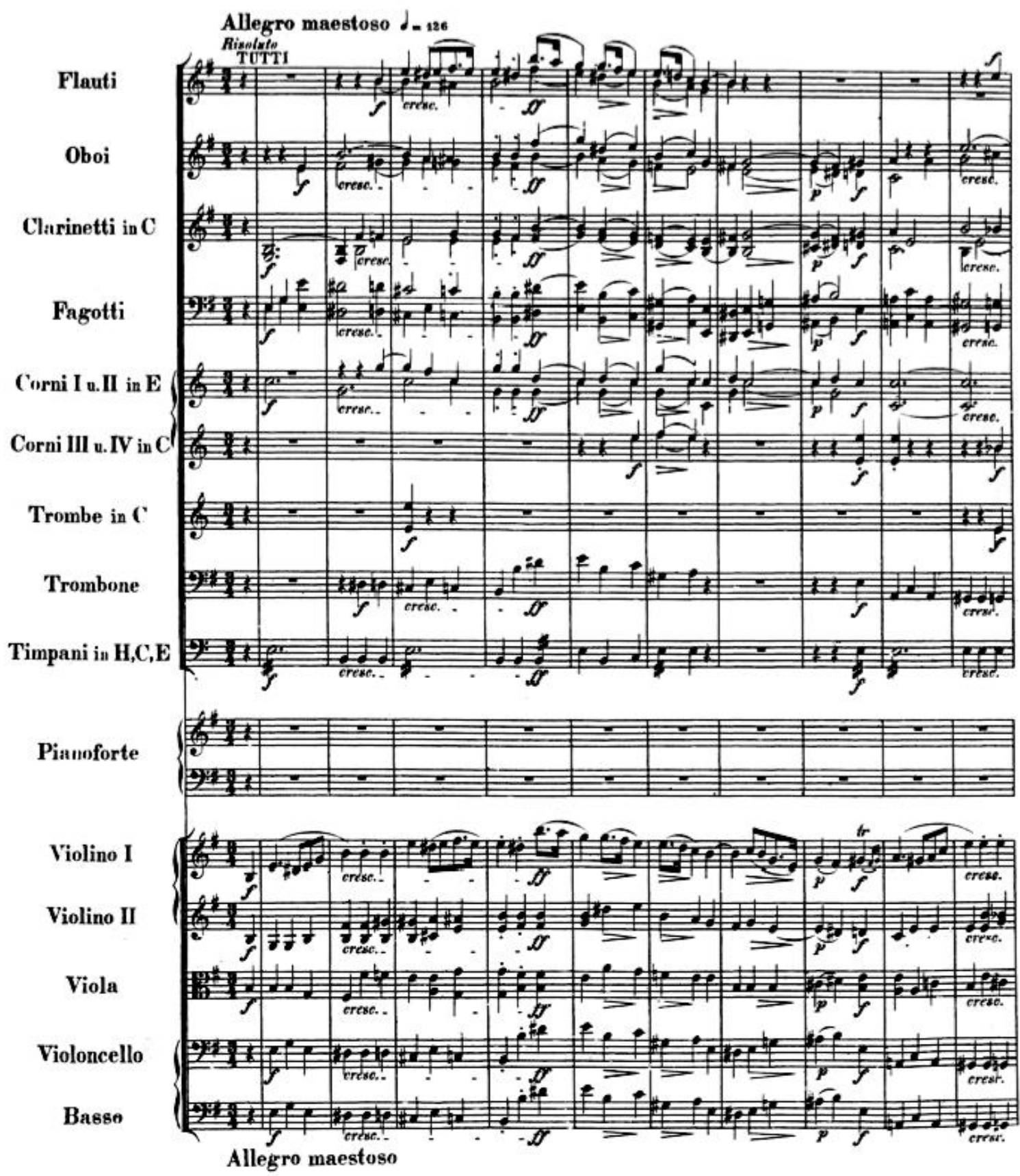

CONCERTO NO. 1 IN E MINOR (I) 3

FIGURE 3: The First page of the score from Frédéric Chopin's Piano Concerto No.1 in E minor, Op. 11. In this score, the different parts are written in separate staves, showing how they will perform together. Image: Damibaru, 1850, Wikimedia Commons.

In design, the concept of a score has been used for writing actions for makers. Anna van der Lei and Kristos Mavrostomos (2014) used the score, borrowing from performance art, to write actions that are descriptions of movements in a space. This resulted in an exploration with glass blowers, where the two designers wrote scores that glass blowers followed in a hot studio workshop. In their exploration, the interpretation of the scores affected the end results. In this experiment, the designers compared glassblowing to dancing and tested the use of a score for designing the choreography for the glass blowers instead of designing the glass objects (van der Lei \& Mavrostomos, 2014, p.162).

In 3D printing, the composer composes a G-code that can be handled as separate data that holds information on the movements and material depositions. The reference to composing is also valid 
when thinking of playing different instruments. Composing can be quite similar in terms of the experience, but it is possible to compose for different instruments. In this case, the instruments could be, for example, a laser cutter, robot arm or 3D printer.

The G-code file consists of digits that the printer reads as movements (Figure 4). In addition to the digits that correspond to motion, the letters in a $G$-code file such as $G, E, F$ hold information on speed or material flow that shapes the characteristics of the final outcome (Figure 7) (Horsanali, 2019).
G1 X20.452 Y-12.557 E88.73500
G1 X21.059 Y-11.512 E89.62031
G1 X21.606 Y-10.447 E90.49763
G1 X22.096 Y-9.368 E91.36597
G1 X22.527 Y-8.278 E92.22444
G1 X22.900 Y-7.183 E93.07219
G1 X23.215 Y-6.086 E93.90847
G1 X23.475 Y-4.992 E94.73258
G1 X23.680 Y-3.904 E95.54389
G1 X23.833 Y-2.826 E96.34187
G1 X23.935 Y-1.761 E97.12588
G1 X23.990 Y-0.692 E97.90989
G1 X23.996 Y0.397 E98.70787
G1 X23.953 Y1.503 E99.51918
G1 X23.856 Y2.624 E100.34329

FIGURE 4: Extract from a G-code. Image: Nur Horsanali, 2020.

The G-code file is comparable to notation. A skilled practitioner in 3D printing can understand the code as it is written and modify it directly. For a beginner, this is solely a file that the digital tool understands and produced by a program. Learning to produce a G-code or to program, is already a prominent creative act in itself and can be compared to composing as it can be understood as a particular expertise and a separate practice.

Clay 3D printing according to a score

In this paper, the concept of a score is used for visualizing the process of clay 3D printing. The full score (Figure 5) describes the entire process. In the full score, the clay 3D printing process is divided into 3 sections: Digital work, 3D Printing and Material work. The division into different parts of the process inside the full process is meaningful, as the 'making' can also solely focus on one strand at the time.

The visualization in Figure 5 shows the full process of clay printing as if it were sheet music / notation. The lines indicate "which notes belong together, thus facilitating score reading" (Gehrkens, 2006, p.108). In written music, the score represents the full sound picture of the piece (Tackley \& Barker, n.d.). Figure 5 is used here to help in examining the full experience of the clay 3D printing process. 


\section{FULL SCORE FOR CLAY 3D PRINTING}


FIGURE 5: Clay 3D printing layout borrowing from score writing. The drawn lines mark the different acts and elements of making described in the text inside the three main parts: digital work, 3D printing and material work. Image: Priska Falin, 2020.

The clay 3D printing process, according to the idea of a full score, visualizes how the full process can be viewed, managed and shared with others. The maker, or the conductor of the full process, can evaluate the different skills needed and how to engage with it or whether to share the process with others and concentrate on a particular part instead of managing the full process.

The staves, in Figure 5, gives an example of how to manage the different parts inside the full process. The lines drawn indicate the action and how it can be combined with other elements, such as 3D scanning can be used when producing the digital file, shown for example, in the part Digital work. The visualization in Figure 5 is only one possibility to manage clay 3D printing and there is many other aspects that can be also indicated in the full score such as material flow, managing the air-pressure, changing the printing speed or adding manual interventions to the print / printing bed. The idea from score writing can be used to manage and creatively engage with an unfamiliar process.

\section{Improvisation within clay 3D printing}

The process of printing can be compared to playing an instrument with the possibility of improvisation. There is a strong performance aspect to 3D printing when the printer starts to work according to the 'notes'. It is performing for the maker as well for others that can follow the unfolding of a printed work (Figure 6). In this performative part of the making, there is the potential to improvise within the process, for example by directly influencing the material flow, managing the air-pressure, changing the printing speed or through manual interventions to the print and printing bed.

The element of controlling the material flow by adjusting the air pressure while printing is a method of accessing the printing process. This part can be compared to playing the instrument and having the element of improvisation while the process is ongoing. With the use of mechanical pressure instead of air pressure, this part of the process changes. This shows how easily small differences in the tools have an impact on the outcomes of the work and the nature of the process. The instruments, or the tools, perform differently and it is up to the maker to learn how to play the particular instrument and experience the varying levels of engagement with the making (Falin \& Falin, 2014). 


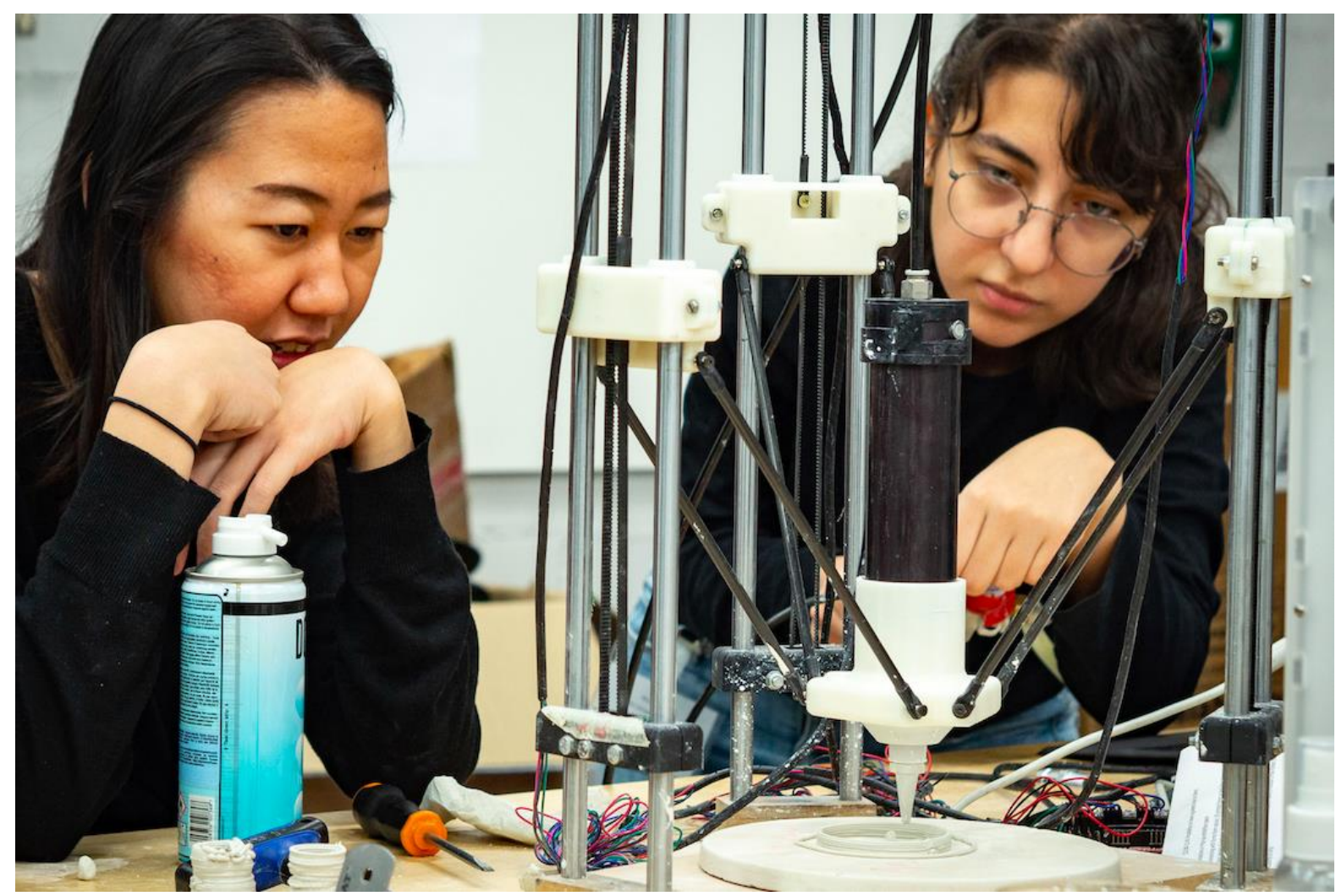

FIGURE 6: The performative part of the printing process with the possibility of improvisation. Photo: Minerva Juolahti, 2019.

Philosopher Alessandro Bertinetto (2012) and psychologist Keith Sawyer (2011) compare the artist's (or designer's) way of working, which allows going back within the making process, to the live setting performance, where the process is irreversible and cannot be corrected. As music has a linear way of becoming, so does the work of a 3D printed process: it is hard to go back in the process while the process is ongoing. Looking at the traditional ways of making in ceramics, the experience is the opposite. With hands-on working with clay, it is possible, for example, to go back in the process, correct shapes, add clay or take it away, or move parts of the making. The printer always adds clay in the same way that a musician cannot take back the notes that she has already played.

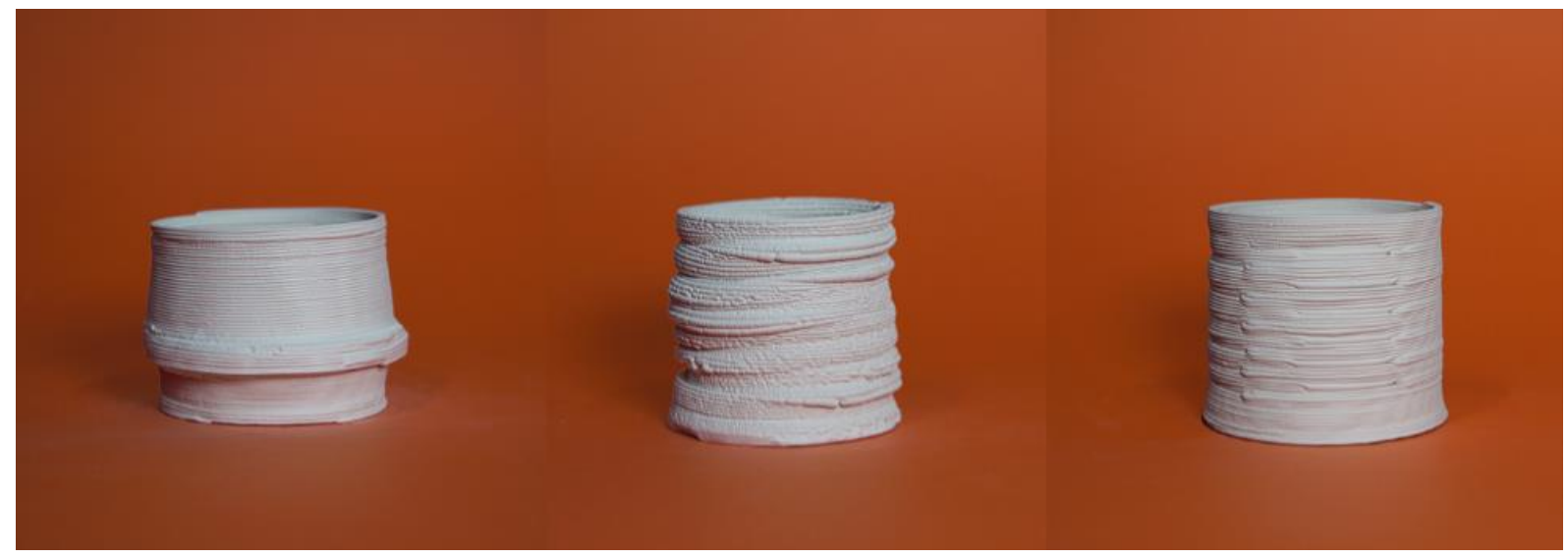

FIGURE 7: Some of the results of improvisation during printing from the practice-led research of Author 2. The original digital form was the same hollow cylinder in each of these prints. Photos: Nur Horsanali, 2019. 


\section{DISCUSSION}

This paper has presented a metaphorical approach for gaining embodied understanding of unfamiliar processes. In this case, the example has been clay 3D printing. The metaphors used have been borrowed from the field of music. In this paper, we have examined musical comparisons such as composing, playing, improvisation and the use of a score for visualizing the nature of the clay 3D printing process. The making of music is a creative act that is already widely understood even if one does not practise it oneself. From this perspective, it is possible to use concepts from the field of music as metaphors to gain an embodied understanding over contemporary practices such as clay 3D printing.

Through metaphorical viewing, practitioners are able to gain an embodied understanding of an unfamiliar contemporary practice. It also enables creative engagement with and exploration of a process that has an ungraspable feel to it. The results in this paper are potentially valuable for practitioners that experience the unfamiliarity of contemporary practices using digital tools. In this case, the embodied understanding embedded in conceptual metaphors can aid in engaging with the elusive processes involving digital tools.

Both making music and the experience of clay 3D printing entail the aspect of sharing and working together. Within the complex digital space in which the maker works, there is always the potential for problems that need others' expertise in order to progress with the work. Hansen \& Tamke (2019) suggest that digital tools can also offer a space for working together. The aspect of sharing influences the authorship of the work. The end result of the working processes shown above is different in nature compared to the work done by one artist in close contact with the materials. A closer examination should focus on how the maker's experience of ownership differs in such situations as when the tool contributes heavily to the outcome or the process is shared with others.

With the lack of openings in the theoretical discussion concerning the act of making with digital tools, the concept of a score was borrowed from the field of music to help in the unfolding of the contemporary practices from the perspective of the maker. The present theorization of making in the creative fields, particularly in artistic research, is rooted in those practices that have direct contacts with the material world. In this discussion, making is seen as close interactions or a dialogue between the maker and the material. However, as this paper shows, the experience of the maker is profoundly different in contemporary practices.

The concept of a score has proven to work well as a descriptive aid in opening up the nature that the abstract and complex structure of contemporary practices can have. The full score is used here to hold the entire process of making from the composing of the digital file to the traditional material work, following the example of clay 3D printing. The score also implies that there is 'making' that is particularly designed with a special instrument in mind and that there is a process that holds elements that can be compared to musical terms, such as composing, playing and working with sound - the material of music. The score suggests that the clay 3D printer is like an instrument and the maker can act as a player that performs the digital file previously composed. With this kind of creative act there is the possibility of improvisation with the 'playing' and interpretation of the digital notes.

\section{CONCLUSIONS}

In this paper, a metaphorical comparison of the making of music and the process of clay 3D printing has been examined in order to gain familiarity using embodied understanding. The concept of a score has been examined to allow the visualization of the full process of clay 3D printing. The explorative use of a score has opened the possibility of how it can aid in managing the contemporary process creatively. The score also implies how the process can be shared with others.

This paper has also opened up the discussion on the different natures of contemporary practice and traditional practice. It has been shown that the use of metaphorical viewing and the concept of a score allows the different experiences within the practice to be investigated in order to uncover subtle nuances, possibilities and limitations. In this manner, further research should be focusing on the different skills and levels of engagement in contemporary practice. This discussion contributes to the theoretical discussions on making from the perspective of the practitioners' experience. 
In addition, this paper has explored musical improvisation during clay 3D printing. Through improvisation the practitioner can adapt to changing situation and to overcome unfamiliarity of the making process. Improvisation, as does managing the scores differently, gives practitioner an explorative approach to printing instead of mere repetition. During improvisation, the maker re-engages with the digital process and gains power over the pre-programmed script that the 3D-printer is performing. This is a prominent finding and more research should focus on this aspect alone.

Furthermore, the framing and the focus of this paper has only been explored via the process of clay 3D printing. Clearly, the concept has the potential to aid in the exploration of other digital tools. Discussions about the difference between other ways of making with a close or immediate connection to material in relation to contemporary practice will inform a better understanding concerning more detailed nuances within making as a wider concept. 


\section{REFERENCES}

Aktaş, B. M. (2018). Material as the co-designer: Exploring a new practice in the nature and at the studio. SYNNYT/ORIGINS, 2018(3), 332-348.

https://wiki.aalto.fi/pages/viewpage.action?pageld=145123907\&preview=/145123907/145124264/16_ Aktas_OK.pdf

Aktaş, B. M., \& Mäkelä, M. (2019). Negotiation between the Maker and Material: Observations on Material Interactions in Felting Studio. International Journal of Design 13(2), 55-67. http://www.ijdesign.org/index.php/IJDesign/article/view/3267/857

Bertinetto, A. (2012). Performing the Unexpected Improvisation and Artistic Creativity. Daimon Revista International de Filosofia, 57, 117-135. https://revistas.um.es/daimon/article/view/153621

Bjerstedt, S. (2014). Storytelling in Jazz Improvisation: Implications of a Rich Intermedial Metaphor. [Doctoral dissertation, Lund University]. https://portal.research.lu.se/portal/en/publications/storytelling-in-jazzimprovisation-implications-of-a-rich-intermedial-metaphor(a8ce01c9-10c4-47fc-bbb3c417c600b18c).html

Bunnell, K. (2004). Craft and digital technology. Keynote speech In World Craft Council 40th Annual Conference, Metsovo, Greece. http://repository.falmouth.ac.uk/537/

Damibaru. (post 1850). The first page of the score from Frédéric Chopin's Piano Concerto No. 1 in E minor, Op. 11. Breitkopf \& Härtel. In Wikimedia Commons. CC BY-SA 4.0. https://commons.wikimedia.org/wiki/File:The_first_page_of_the_score_from_Fr\%C3\%A9d\%C3\%A9ric_ Chopin\%27s_Piano_Concerto_No._1_in_E_minor,_Op._11.png

Dewey, J. (2005/1934). Art as experience. TarcherPerigee.

Dufva, T. (2018). Art education in the post-digital era: Experiential construction of knowledge through creative coding. [Doctoral dissertation. Aalto University]. https://aaltodoc.aalto.fi/handle/123456789/31304

Dufva, T., \& Dufva, M. (2019). Grasping the future of the digital society. Futures, 107, 17-28. https://doi.org/10.1016/j.futures.2018.11.001

Encyclopædia Britannica. (2017). Score. In Encyclopædia Britannica. Retrieved October 23, 2020, from https://www.britannica.com/art/score-music

Falin, P. (2014). Connection to materiality: Engaging with ceramic practice. Ruukku: Studies in Artistic Research, 2, 1-9._https://doi.org/10.22501/ruu.44836

Falin, P., \& Falin, P. (2014). Making and perceiving: Exploring the degrees of engagement with the aesthetic process. In Y-k. Lim, K. Niedderer, J. Redström, E. Stolterman \& A. Valtonen (Eds.) Proceedings of DRS2014: Design's big debates (pp. 1612-1625). Umeå Institute of Design, Umeå University.

Fors, A. C. (2010). The beauty of the beast: the matter of meaning in digitalization. Al \& Society Special Issue: Ethics and Aesthetics of Technologies, 25(1), 22-33. https://doi.org/10.1007/s00146-009-0236-z

Gehrkens, K. W. (2006) Music Notation and Terminology. The Project Gutenberg eBook. https://www.gutenberg.org/files/19499/19499-h/19499-h.htm\#Page_101

Groth, C. (2017). Making Sense Through Hands. Design and Craft Practice Analysed as Embodied Cognition. [Doctoral dissertation, Aalto University]. https://aaltodoc.aalto.fi/handle/123456789/24839

Gürsoy, B. (2018). From Control to Uncertainty in 3D Printing with Clay. In Kepczynska-Walczak, A. Bialkowski, S. (Eds.) Proceedings of the $36^{\text {th }}$ eCAADe Conference: Computing for a better tomorrow (pp. 21-30). Lodz University of Technology. http://papers.cumincad.org/data/works/att/ecaade2018_104.pdf

Hansen, F. T. (2013). An Experiment with The Voice to Design Ceramics. In E. Brandt, P. Ehn, T. D. Johansson, M. H. Reimer, T. Markussen and A. Vallgårda (Eds.) Proceedings of Nordes2013: Experiments in design research (pp. 358-361). http://conference2013.nordes.org/pictures/Nordes2013Proceedings.pdf

Hansen, F. T., \& Falin, P. (2016). 3D Printing as a Ceramic Craft Tool in Its Own Right. In M. Mäkelä, B. Schmidt, P. Falin and M. Juolahti (Eds.), Ceramics and its Dimensions: Shaping the Future (pp. 114-128). Aalto University. http://urn.fi/URN:ISBN:978-952-60-7041-4 
Hansen, F. T., \& Tamke, M. (2019). A Visual Programming Interface as the Common Platform for Sharing Embodied Knowledge. In N. Nimkulrat, K. Kuusk, J. V. Noronha, C. Groth \& O. Tomico (Eds.) Proceedings of EKSIG2019: Knowing Together: Experiential knowledge and Collaboration (56-70). Estonian Academy of Arts. https://eksig2019.artun.ee/wp-content/uploads/2019/09/3.pdf

Horsanali, N. (2019). Digitalization meets improvisation: Developing a personal way of dealing with the rising digital presence in design. (Master's thesis) Aalto University.

Ingold, T. (2010). The Textility of making. Cambridge Journal of Economics 2010, 34, 91-102. https://doi.org/10.1093/cje/bep042

Johnson, M. (2015). Embodied understanding. Frontiers in Psychology, 6, Article 875. https://doi.org/10.3389/fpsyg.2015.00875

Klein, T. (2008). Augmented Fauna and Glass Mutations: A Dialogue Between Material and Technique in Glassblowing and 3D printing. Leonardo, 51(4), 336-342.

Lakoff, G. \& Johnson, M. (1999). Philosophy in the flesh: The embodied mind and its challenge to western thought. Basic Books.

Malafouris, L. (2008). At the Potter's Wheel: An Argument for Material Agency. In C. Knappett \& L. Malafouris (Eds.), Material Agency: Towards a non-anthropocentric approach (pp. 19-36). Springer. https://doi.org/10.1007/978-0-387-74711-8_2

Maravita, A., \& Iriki, A. (2004). Tools for the body (schema). TRENDS in Cognitive Sciences, 8(2), 79-86. https://doi.org/10.1016/j.tics.2003.12.008

McCullough, M. (1998). Abstracting Craft: The Practiced Digital Hand. MIT Press.

Mäkelä, M. (2007). Knowing Through Making: The Role of the Artefact in Practice-led Research. Knowledge, Technology \& Policy, 20(3), 157-163. https://doi.org/10.1007/s12130-007-9028-2

Mäkelä, M. (2016). Personal exploration: Serendipity and intentionality as altering positions in a creative process. FORMakademisk 9(1), Article 2, 1-12. http://dx.doi.org/10.7577/formakademisk.1461

Niedderer, K. (2007). Mapping the Meaning of Knowledge in Design Research. Design Research Quarterly, 2(2), 113. http://hdl.handle.net/2436/38736

Nimkulrat, N. (2009). Paperness: Expressive Material in Textile Art from and Artist's Viewpoint. [Doctoral dissertation, University of Art and Design, Helsinki]. https://aaltodoc.aalto.fi/handle/123456789/11893

Omholt, K. (2019). Tying Knots: Creating Metaphors for Interpersonal Relationships. SYNNYT/origins: Research in Art Education, (3), 1-13.

https://wiki.aalto.fi/download/attachments/172982823/Knut_Omholt.pdf?version=1\&modificationDate $=1589292660749 \&$ api $=$ V2

Pallasmaa, J. (2009). The thinking hand: Existential and embodied wisdom in architecture. Wiley.

Rushkoff, D. (2010). Program Or Be Programmed: Ten Commands for a Digital Age. OR Books. https://doi.org/10.2307/j.ctt207g7rj

Sawyer, R. K. (2011). Improvisation. In M. Runco \& S. Pritzker (Eds.), Encyclopedia of Creativity (2nd ed., pp. 647652). Academic Press/Elsevier. https://doi.org/10.1016/B978-0-12-375038-9.00120-5

Sennett, R. (2008). The Craftsman. Penguin Books.

Tackley, C. \& Barker, N. (n.d). Understanding musical scores. In Open Learn by The Open University. https://www.open.edu/openlearn/ocw/mod/oucontent/view.php?id=26859\&section=1

Thomsen, M. R., Tamke, M., \& Pedersen, C. P. (2012). Digital Crafting, A network on Computation and Craft in Architecture, Engineering and Design. http://www.digitalcrafting.dk/

Yamamoto, Y., Uchiyama, H., \& Kakehi, Y. (2011). onNote: playing printed music scores as a musical instrument. In Proceedings of the 24th annual ACM symposium on User interface software and technology (pp. 413422). https://doi.org/10.1145/2047196.2047249

van der Lei, A., \& Mavrostomos, K. (2014). A Dialogue with Glass. [Unpublished Master's thesis]. Aalto University. 
Verbruggen, D. (2014). The Digital Craftsman and His Tools. In All Makers Now: Craft Values in 21st Century Production - Conference Proceedings (pp. 173-177). Falmouth: Falmouth University. http://unfold.be/pages/the-digital-craftsman-and-his-tools-essay 